\title{
Caracterização e classificação dos resíduos de construção civil da cidade de Fortaleza (CE)
}

\section{Characterization and classification of construction waste in Fortaleza (CE)}

\author{
Adriana Sampaio Lima \\ Mestre em Tecnologia e Gestão Ambiental pelo Instituto Federal de Educação, Ciência e Tecnologia do Ceaŕa (IFCE). \\ Técnica de Laboratório de Biologia do IFCE - Crateús (CE), Brasil. \\ Antonio Eduardo Bezerra Cabral \\ Doutor em Ciências da Engenharia Ambiental pela Universidade de São Paulo (USP). Professor do Programa de \\ Pós-Graduação em Engenharia Estrutural e Construção Civil (PEC) da Universidade Federal do Ceará (UFC) - Fortaleza (CE), Brasil.
}

\section{Resumo}

Este estudo visa analisar a composição gravimétrica, avaliar parâmetros químicos e classificar os Resíduos de Construção Civil (RCC) da cidade de Fortaleza de acordo com a Resolução CONAMA n 307 e com a NBR 10004. Os resultados indicam que o RCC de Fortaleza é composto por 93,40\% do Grupo A, 6,40\% do Grupo B, 0,02\% do Grupo C e 0,20\% Grupo D. O primeiro é composto principalmente por areia e solo (24,65\%) e argamassa (22,00\%), que são materiais com alto potencial de reutilização ou reciclagem. Além disso, de acordo com a análise química, o RCC de Fortaleza mostrou alta variabilidade em todos os

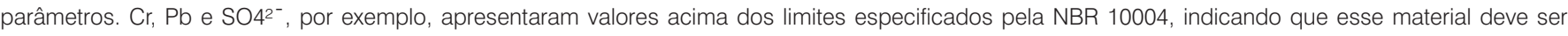
classificado como Classe II-A (não perigoso e não inerte).

Palavras-chave: RCC; caracterização física e química; classificação; resolução CONAMA nº 307; Fortaleza.

\section{Abstract}

This study aims to analyze the gravimetric composition, evaluate chemical parameters and classify the construction waste (CW) of Fortaleza city according to CONAMA Resolution N 307 and to NBR 10004. Results show that Fortaleza's CW is composed by 93,40\% of Group A, 6,40\% Group B, $0,02 \%$ Group C and 0,2\% Group D. The first is composed primarily by sand and gravel $(24,65 \%)$ and mortar $(22,00 \%)$, that are materials with high potential for reuse or recycling. Moreover, according to chemical analysis, Fortaleza's CW showed a high variability in all parameters. Cr, Pb and $\mathrm{SO}^{2-}{ }^{-}$, for example, showed above to the limits specified by NBR 10004, indicating that this material have to be classified as Class II-A (not dangerous and not inert).

Keywords: CW; chemical and physical characterization; classification; CONAMA resolution 307; Fortaleza. 


\section{Introdução}

A construção civil é um dos setores que mais cresce no mundo, sendo reconhecida como uma importante atividade para o desenvolvimento econômico e social (HALMEMAN; SOUZA; CASARIN, 2009). Como paradoxo, é uma atividade de grande impacto ambiental, apresentando elevada utilização de recursos naturais para a produção de bens de consumo e sendo responsável por grande parte dos resíduos sólidos gerados atualmente. Em 2005 era estimada geração de 68,5 milhões de toneladas pela indústria da construção do total de resíduos industriais produzidos (ANGULO, 2005). Eguchi et al (2007), citado por Lovato (2007), estimaram essa geração em 75 milhões de toneladas e que os resíduos de construção civil (RCC) representam, em média, 50\% da massa dos resíduos sólidos urbanos (RSU).

A questão ambiental na atividade da construção civil ganhou relevância nos últimos anos, assim como a preocupação com a escassez de recursos naturais, os impactos causados ao meio ambiente, e a geração e deposição inadequadas de resíduos. Eles causam efeitos irreversíveis ao meio ambiente e têm levado a um novo conceito de construção sustentável, baseado na prevenção e redução de resíduos sólidos com a utilização de tecnologias limpas e materiais recicláveis e reutilizáveis (VAZQUEZ, 2001).

A reciclagem dos RCC é uma alternativa para economizar os recursos naturais utilizados como matéria-prima na construção civil, além de uma possibilidade de redução nos custos de construção e do volume final dos resíduos a serem dispostos.

O RCC contém muitos materiais passíveis de reciclagem ou reutilização. De acordo com Oliveira et al. (2005), citado por Oliveira e Mendes (2008), em Goiás, 60\% do RCC gerado pode ser reutilizado. O resíduo de construção em Salvador é composto, em sua maior parte, por restos de concreto e argamassa (equivalentes a 53\%), enquanto 22\% é solo e areia, tendo estes materiais alto potencial de reciclagem para a produção de agregados reciclados (CARNEIRO.; BRUM; CASSA, 2001).

Uma das etapas imprescindíveis para estudos de alternativas que visem a reciclagem dos RCC é a sua caracterização, tanto na forma bruta quanto na reciclada (CARNEIRO.; BRUM; CASSA, 2001), pois os fatores de geração e a composição podem interferir diretamente na qualidade do agregado reciclado produzido. A análise da composição gravimétrica dos resíduos de construção civil é um importante parâmetro a ser considerado quando se trata de sistemas de tratamento e disposição final desses resíduos. A determinação das diferentes frações dos componentes fornece alternativas de tratamento e aproveitamento do RCC (CORNELLI et al., 2006).

No Brasil são muitos os trabalhos de pesquisas tecnológicas envolvendo o uso sustentável de RCC que comprovam a viabilidade técnica destes resíduos como agregado reciclado para a fabricação de argamassas (ASSUNÇÃO; CARVALHO; BARATA, 2007), concretos (CABRAL, 2007), utilização em pavimentos (LIMA, 2008) e estruturas de solo reforçado (SANTOS, 2007). A possibilidade de utilização de um resíduo deve ser avaliada tanto pelas características técnicas que se deseja, quanto pelos possíveis impactos ambientais que possa causar (SILVA e ARNOSTI Jr., 2007).

A NBR 10004 (ABNT, 2004a) classifica os resíduos quanto aos seus potenciais riscos ambientais em Classe I - perigosos, Classe II A - não perigosos e não inertes, e Classe II B - não perigosos e inertes. Por ser usualmente considerado inerte, o RCC já é bastante utilizado como agregado reciclado em obras de pavimentação e na construção de casas populares por prefeituras de cidades brasileiras, como é o caso de Fortaleza, onde foi criado um conjunto habitacional composto de 20 casas utilizando tijolo reciclado e material de escavação de obras (MAYORGA et al., 2009). Entretanto, estes resíduos podem conter impurezas e contaminantes provenientes de polímeros, gesso, matéria orgânica, amianto, sílica e diversas substâncias reativas capazes de contaminar o solo e os recursos hídricos e, ainda, ocasionar riscos à saúde humana.

Estudos realizados em algumas cidades brasileiras, como Vitória (RAMOS, 2007) e Piracicaba (SILVA e ARNOSTI Jr., 2007), mostram, por meio de ensaios químicos, que os RCC devem ser classificados como Classe II A - não perigoso e não inerte. Oliveira (2002) constatou que resíduos de concreto da cidade de Rio Claro também devem ser considerados classe II A. Em Fortaleza, não há estudos sobre resíduos de construção civil relacionados aos seus potenciais riscos ambientais, portanto, não há confirmação de que os RCC devam ser considerados Classe II B - não perigoso e inerte, de acordo com a NBR 10004 (ABNT, 2004a).

Para o máximo aproveitamento dos resíduos de construção civil de Fortaleza na reciclagem e reutilização, faz-se necessário o levantamento de indicadores de qualidade por meio da caracterização física e do estudo das características químicas dos RCC, objetivo deste artigo, identificando o seu potencial uso como agregado reciclado, minimizando, assim, os impactos ambientais e contribuindo para a sustentabilidade na construção civil.

\section{Metodologia}

Para realização da caracterização e composição física dos RCC de Fortaleza foram determinados dois locais de coleta, que são áreas licenciadas para recebê-los, sendo uma área em recuperação e uma usina de reciclagem. As coletas foram realizadas durante os meses de janeiro, abril, julho e setembro de 2011, totalizando quatro amostras de aproximadamente $280 \mathrm{~kg}$ cada. As amostras referentes a janeiro e abril, denominadas AM1 e AM2, respectivamente, foram coletadas na área em recuperação; e as de julho e setembro (AM3 e AM4, respectivamente), em uma usina de reciclagem.

As coletas seguiram as recomendações da NBR 10007 (ABNT, 2004d). Ao final de cada uma delas, passaram por um processo de homogeneização e quarteamento para a obtenção de uma amostra representativa. A segregação dos resíduos presentes foi realizada manualmente 
e os grupos de materiais definidos conforme adaptação de metodologia de CARNEIRO.; BRUM; CASSA (2001) e Ramos (2007). Os grupos de resíduos foram enquadrados em classes estabelecidas pela Resolução no 307 (BRASIL, 2002), ou seja, nas classes A, B, C e D.

Para a classificação química de acordo com a NBR 10004 (ABNT, 2004a), foram realizadas análises de solubilidade e toxicidade do resíduo Classe A. Os extratos para a análise de toxicidade (lixiviado) e solubilidade (solubilizado) foram preparados de acordo com as recomendações da NBR 10005 (ABNT, 2004b) e NBR 10006 (ABNT, 2004c, respectivamente. Já os parâmetros utilizados na análise da toxicidade e da solubilidade foram determinados segundo os anexos F e G da NBR 10004 (ABNT, 2004a), respectivamente. O Quadro 1 apresenta os parâmetros analíticos investigados nos testes de toxicidade e solubilidade realizados. A análise de todos os parâmetros seguiu metodologia descrita no Standard Methods for the Examination of Water and Wastewater (APHA, 2005).

\section{Resultados e discussão}

\section{Composição gravimétrica e classificação segundo a resolução CONAMA $n^{0}$ 307/2002}

A composição gravimétrica das amostras coletadas e a classificação segundo a Resolução CONAMA n 307/2002 estão apresentadas na Tabela 1, a partir da qual se verifica que os resíduos de construção civil de Fortaleza são heterogêneos. Entretanto, em todas as amostras de RCC coletadas, o resíduo Classe A é o que possui maior participação na composição gravimétrica, com percentual médio de 93,4\%.

A argamassa foi o material que apresentou o maior percentual em três das quatro amostras coletadas em Fortaleza (média de 22\%), enquanto o concreto e o tijolo branco registraram 15,6\% e 10,4\%, respectivamente. Para Oliveira et al. (2011), o concreto é o segundo material que mais contribui para os RCC, com média de 14\%. Em Vitória (ES), Ramos (2007) relata que são poucas as ocorrências de demolições de estruturas de concreto, o que influencia na pequena quantidade do material (9,61\% do total de RCC).

O grupo areia e solo obteve percentual médio de 24,6\%. Em Salvador (BA), de acordo com estudos realizados por Carneiro.; Brum; Cassa, (2001), atinge 22\%. Por outro lado, em Vitória (ES) é o constituinte que mais prevalece nos RCC (RAMOS, 2007).

Os grupos cerâmica vermelha e cerâmica de revestimento apresentaram percentual de $14,4 \%$ e 6,3\%, respectivamente. Os resultados obtidos corroboram com estudos realizados em cidades brasileiras como Vitória (RAMOS, 2007), Salvador (CARNEIRO.; BRUM; CASSA, 2001) e Fortaleza (OLIVEIRA et al., 2011).

Os resíduos Classe B apresentaram percentual médio de 6,4\%, resultado próximo ao obtido por Ramos (2007) para a cidade de Vitória, em que variaram entre 4,8 e 13,0\%.
Quadro 1 - Parâmetros analisados para as análises de toxicidade e solubilidade.

\begin{tabular}{|c|c|}
\hline Análise & Parâmetros analíticos \\
\hline Toxicidade & $\mathrm{Ag}, \mathrm{As}, \mathrm{Ba}, \mathrm{Cd}, \mathrm{Cr}, \mathrm{Hg}, \mathrm{Pb}, \mathrm{Se}$ e $\mathrm{F}^{-}$ \\
\hline Solub & $\begin{array}{l}\mathrm{Ag}, \mathrm{As}, \mathrm{Al}, \mathrm{Ba}, \mathrm{Cd}, \mathrm{Cr}, \mathrm{Cu}, \mathrm{Fe}, \mathrm{Hg}, \mathrm{Mn}, \mathrm{Na}, \mathrm{Pb}, \mathrm{Se}, \mathrm{Zr} \\
\mathrm{Cl}^{-}, \mathrm{F}^{-}, \mathrm{NO}^{-}, \mathrm{SO}^{2}{ }^{-}, \mathrm{CN}^{-} \text {e Fenol }\end{array}$ \\
\hline
\end{tabular}

O grupo "Outros", constituído por plástico, madeira, papelão, vidro e metais, teve resultados percentuais semelhantes em todas as amostras, variando de 1,2 a 2,0\% do total dos RCC. Eles são encontrados em menor quantidade, já que Fortaleza instituiu em 2006 o seu Plano de Gerenciamento de Resíduos da Construção Civil, que obriga os grandes geradores, no caso, as empresas construtoras, a elaborar e executar um Plano de Gerenciamento dos Resíduos Sólidos (PGRS) da obra, de acordo com a Resolução CONAMA n 307/2002. Após devidamente segregados na obra, estes resíduos são comercializados pelas próprias construtoras, ou seja, a quantidade descartada é pequena. Dados da Cooperativa dos Construtores do Estado do Ceará (COOPERCON-CE) confirmam esta informação. Segundo seus estudos em obras verticais da capital cearense, a quantidade de resíduos Classe B soma apenas 10\% (NOVAES \& MOURÃO, 2008).

Ocorre também destes materiais serem recolhidos por catadores, que os vendem para empresas de reciclagem antes de serem recolhidos para a destinação final.

A presença de gesso nas amostras de RCC de Fortaleza se mostrou praticamente constante, com percentuais entre 4,9 e 5,1\%. O gesso tem em sua composição principal o sulfato de cálcio duplamente hidratado, substância expansiva que pode contaminar o RCC, tornando-o inviável para a reciclagem.

Os materiais pertencentes à Classe $\mathrm{C}$, de acordo com a Resolução CONAMA no 307/2002 (BRASIL, 2002), são os que não possuem tecnologia ou são inviáveis, em termos técnicos, para a reutilização ou reciclagem. Das quatro amostras coletadas, apenas na AM4 foi identificado material como espuma, couro e tecido, com porcentagem mínima de $0,1 \%$, resíduos geralmente descartados em lixo comum. Em 25\% das amostras coletadas em Vitória por Ramos (2007), o material pertencente à Classe $\mathrm{C}$ aparece como o menos gerado, com percentuais que variam entre 0,12 e 2,37\%, sendo estes mais elevados do que os observados em Fortaleza.

Embalagens de tinta, solventes e amianto são materiais pertencentes à Classe D (resíduos perigosos), de acordo com a Resolução CONAMA no 307 (BRASIL, 2002), portanto, não deveriam estar presentes em aterros e usinas de reciclagem de RCC. As AM2 e AM4 indicaram percentuais de 0,2 e 0,6\% destes materiais, respectivamente. A quantidade observada é pequena quando comparada ao total de RCC nos locais de disposição final, entretanto, mesmo presente em pequena escala, eles têm alto potencial de contaminação para o meio ambiente e para a saúde pública. São necessários critérios para o gerenciamento dos resíduos Classe $\mathrm{D}$, que devem ser depositados em locais destinados a resíduos perigosos. 
Tabela 1 - Percentual de composição e classificação dos resíduos de construção civil da cidade de Fortaleza.

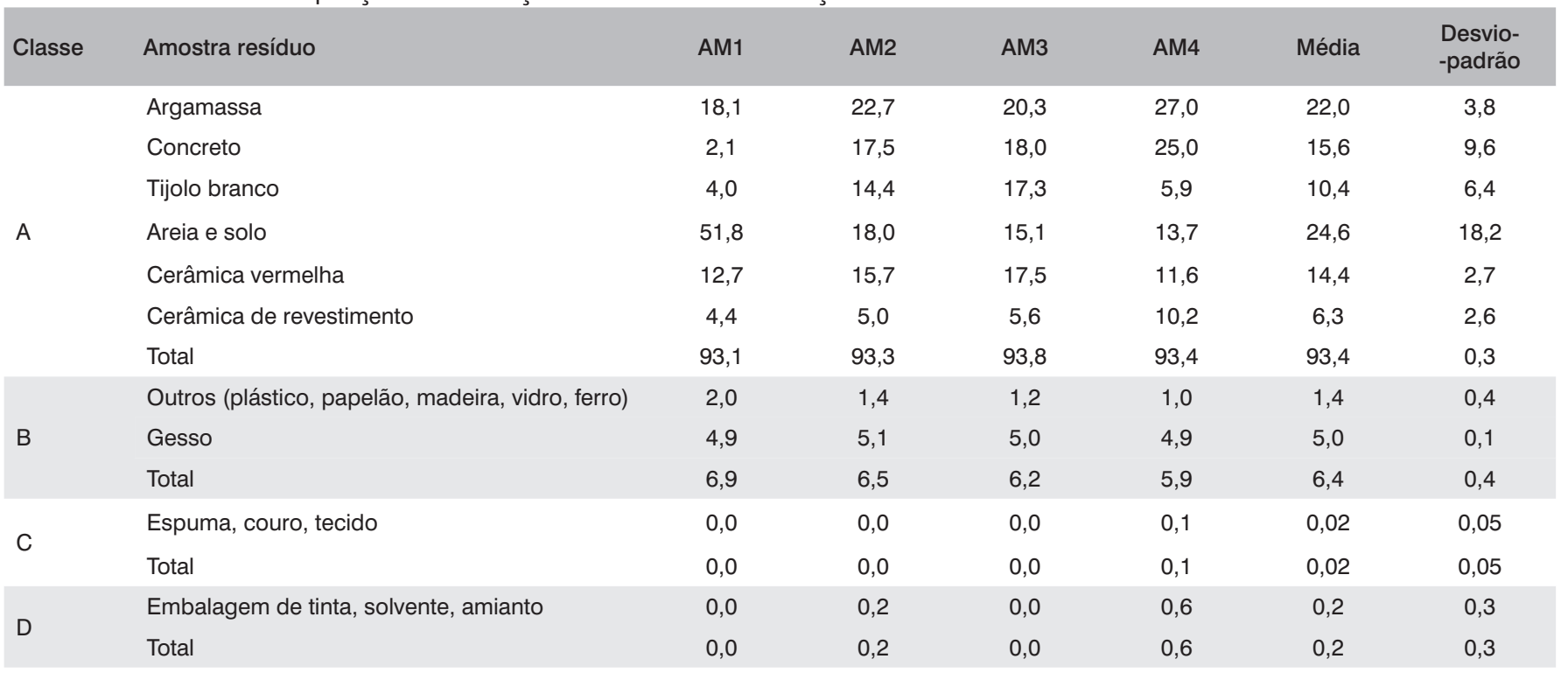

\section{Classificação química segundo a NBR 10004 (ABNT, 2004a)}

\section{Análise de toxicidade}

Os resultados das concentrações dos constituintes e do $\mathrm{pH}$ nas amostras do extrato lixiviado para a análise de toxicidade estão apresentados na Tabela 2, que mostra ainda o limite máximo permitido para cada constituinte de acordo com o anexo F da NBR 10004 (ABNT, 2004a).

$\mathrm{O}$ pH das amostras AM1 e AM2 foram levemente alcalinos enquanto nas AM3 e AM4 se apresentaram levemente ácidos. Segundo Schaefer, Rocha e Cheriaf (2007), um fator que pode contribuir para a alcalinidade do extrato lixiviado é o volume de água limitado, pois no meio ambiente as condições diferem das propostas no ensaio, uma vez que o volume de água é ilimitado, induzido a diferentes condições de lixiviação. Para a análise de metais, as amostras foram acidificadas, uma vez que ambientes ácidos favorecem a mobilidade de metais pesados, que se tornam mais solúveis.

Os resultados apresentados na Tabela 2 demonstram que, apesar de todos os componentes analisados serem lixiviados quando em condições de chuva ácida, nenhum parâmetro verificado nos extratos das amostras de RCC de Fortaleza apresentou concentrações superiores aos limites máximos estabelecidos pela NBR 10004 (ABNT, 2004a). Verifica-se ainda que alguns parâmetros, como arsênio, mercúrio, prata e selênio, apresentaram concentrações ínfimas quando comparadas ao limite máximo.

Togerö (2004) demonstrou que o chumbo é lixiviado pela chuva e que metais pesados de concreto contendo aditivos e adições também podem ser rapidamente lixiviados. A Tabela 2 indica que houve lixiviação de chumbo nas amostras testadas, entretanto, este não alcançou valores superiores ao limite máximo.

Schaefer, Rocha e Cheriaf (2007) obtiveram resultados semelhantes quando analisaram extratos lixiviados de argamassa produzida com agregado reciclado provenientes de RCC e verificaram que metais pesados como arsênio, cádmio, cromo e selênio são lixiviados das argamassas produzidas, entretanto, nenhum parâmetro ultrapassou os limites recomendados pela NBR 10004 (ABNT, 2004a). Porém os autores ressaltaram que os mesmos resultados, quando comparados aos limites da diretiva europeia 98/93/EC, apresentaram-se superiores aos recomendados.

Os limites máximos permitidos pela diretiva europeia 98/93/EC são bem inferiores quando comparados aos indicados pela NBR 10004 (ABNT, 2004a). Por exemplo: o limite de cromo lixiviado na diretiva europeia 98/93/EC é 0,05 mg/.L e na NBR 10004 atinge 5,0 mg/.L-1. Se fossem levados em consideração os limites europeus, três amostras de extrato lixiviado do RCC Classe A de Fortaleza estariam contaminadas com cromo. O mesmo ocorreria com a análise de cádmio, considerando que nas quatro amostras analisadas se apresenta acima do limite máximo europeu $\left(0,005 \mathrm{mg} / \mathrm{L}^{-1}\right)$

Ramos (2007), em seu trabalho sobre indicadores de qualidade, analisou 12 amostras de RCC da cidade de Vitória e concluiu que em $100 \%$ delas os RCC foram classificados como não tóxicos, de acordo com a NBR 10004. Cassa et al. (2001), após avaliação de toxicidade em agregados reciclados graúdo e miúdo, constataram que os produzidos na cidade de Salvador também devem ser mensurados como não tóxicos.

Em geral, os resultados mostram que, a partir das amostras analisadas, apesar de os RCC Classe A de Fortaleza serem classificados como não tóxicos, há a presença de metais pesados que podem contaminar o meio ambiente e serem prejudiciais à saúde humana. 
Tabela 2 - Resultado da análise de toxicidade nas amostras de resíduos de construção civil de Fortaleza pelo extrato lixiviado.

\begin{tabular}{|c|c|c|c|c|c|}
\hline \multirow{2}{*}{ Parâmetros } & \multicolumn{4}{|c|}{ Extrato lixiviado $\left(\mathrm{mg} / \mathrm{L}^{-1}\right)$} & \multirow{3}{*}{$\begin{array}{l}\text { Limite máximo do } \\
\text { extrato }\left(\mathrm{mg} / \mathrm{L}^{-1}\right)\end{array}$} \\
\hline & AM1 & AM2 & AM3 & AM4 & \\
\hline $\mathrm{pH}$ & 7,19 & 7,69 & 5,53 & 6,08 & \\
\hline Arsênio & $<0,001$ & $<0,001$ & $<0,001$ & $<0,001$ & 1,0 \\
\hline Bário & 0,140 & $<0,01$ & 0,290 & 0,060 & 70,0 \\
\hline Cádmio & 0,178 & 0,096 & 0,150 & 0,095 & 0,5 \\
\hline Chumbo & 0,167 & 0,172 & 0,110 & 0,235 & 1,0 \\
\hline Cromo & 0,024 & 0,130 & 0,051 & 0,103 & 5,0 \\
\hline Mercúrio & $<0,001$ & $<0,001$ & $<0,001$ & $<0,001$ & 0,1 \\
\hline Prata & $<0,01$ & $<0,01$ & $<0,01$ & $<0,01$ & 5,0 \\
\hline Selênio & $<0,01$ & $<0,01$ & $<0,01$ & $<0,01$ & 1,0 \\
\hline Fluoreto & 0,770 & 0,730 & 0,730 & 0,950 & 150,0 \\
\hline
\end{tabular}

\section{Análise de solubilidade}

Os resultados da análise de solubilidade em água, de acordo com a NBR 10004 (ABNT, 2004a), e o pH das amostras estão dispostos na Tabela 3, que apresenta também o limite máximo permitido de acordo com o Anexo G da NBR 10004 (ABNT, 2004a). Segundo Ramos (2007), a solubilização simula o desprendimento de constituintes em uma situação de chuva não ácida. As análises dos parâmetros relacionados na Tabela 3 indicam a possibilidade de desprendimento destes constituintes em ambiente natural, podendo ocasionar a contaminação do solo ou de recursos hídricos.

Verifica-se que nas quatro amostras analisadas foram encontrados parâmetros inorgânicos (alumínio, cádmio, chumbo, cromo e sulfato) acima do limite permitido pela NBR 10004 (ABNT, 2004a). Os extratos solubilizados de todas as amostras de RCC Classe A de Fortaleza apresentaram concentrações dos parâmetros arsênio, bário, cobre, ferro, manganês, mercúrio, prata, selênio, sódio, zinco, nitrato, fenóis, cloreto, fluoretos e cianetos abaixo dos limites máximos permitidos pela NBR 10004 (ABNT, 2004a).

$\mathrm{Na}$ amostra AM4, o alumínio foi encontrado na concentração de $0,31 \mathrm{mg} / . \mathrm{L}^{-1}$ Este resultado está acima do limite máximo $\left(0,2 \mathrm{mg} / \mathrm{L}^{-1}\right)$. Nas demais amostras, ele se solubilizou em quantidade inferior ao limite máximo permitido.

Análises em RCC reciclados na cidade de Piracicaba realizadas por Silva e Arnosti Jr. (2007) constaram a presença de teor de alumínio acima do limite máximo permitido pela NBR 10004. Ramos (2007) também verificou alto teor de alumínio em uma de suas amostras de RCC da cidade de Vitória.

Carneiro; Brum; Cassa (2001) explicam que a existência de altos teores de alumínio em RCC pode ser devido à presença de concreto de cimento aluminoso. Entretanto, este tipo de cimento não é comum no Brasil, sendo mais utilizado o Portland composto (CPII), que contém em sua composição óxido de alumínio $\left(\mathrm{Al}_{2} \mathrm{O}_{3}\right)$.
Ulsen et al. (2010) verificaram que em agregados mistos de RCC da cidade de São Paulo a quantidade de óxido de alumínio ou alumina $\left(\mathrm{Al}_{2} \mathrm{O}_{3}\right)$ variou entre 4,7 e 11,0\% e concluíram que o composto estava relacionado à presença, principalmente, de cerâmica vermelha e cimento. É possível que a alta concentração de alumínio nos RCC de Fortaleza seja proveniente do óxido de alumínio presente em cimentos Portland, visto que os teores de argamassa e concreto somam, em média, aproximadamente 38\% dos RCC, e das cerâmicas vermelhas, que correspondem em média a 14\% dos RCC. Altas quantidades de alumínio podem contaminar a água, oferecendo riscos à saúde humana.

As quatro amostras de extrato solubilizado apresentaram presença de cádmio acima do limite permitido. Na AMl e AM2, a concentração de cádmio foi aproximadamente 20 vezes maior que o limite máximo permitido pela NBR 10004. Já na AM3 e AM4 os valores encontrados foram um pouco menores em relação às amostras AM1 e AM2, mas ainda bastante elevadas, pois registraram concentração entre 10 e 15 vezes maior que o permitido pela NBR 10004. O cádmio é mais utilizado na fabricação de baterias de níquel-cádmio encontradas em telefones celulares e equipamentos sem fio. Entretanto, também é empregado no revestimento de metal, algumas tintas e plásticos, materiais presentes em RCC, o que justificaria a sua alta concentração nas amostras dos RCC de Fortaleza.

Outros parâmetros com concentrações acima do limite máximo permitido foram o chumbo e o cromo, com média de 0,107 mg/..-1 e $0,165 \mathrm{mg} / \mathrm{L}^{-1}$, respectivamente. Isso pode ser explicado pela quantidade de RCC originados de demolições, pois estes resíduos contêm tintas, vernizes e outros materiais para acabamento que possuem chumbo e cromo em sua composição (SILVA e ARNOSTI Jr., 2007). Ambos têm sua utilização em tintas regulamentada, e a tinta é classificada pela NBR 10004 (ABNT, 2004a) como resíduo perigoso. Os resíduos de tinta contaminam os RCCs e, consequentemente, os 
Tabela 3 - Resultado da análise de solubilidade nas amostras de resíduos da construção civil de Fortaleza.

\begin{tabular}{|c|c|c|c|c|c|}
\hline \multirow{2}{*}{ Parâmetros } & \multicolumn{4}{|c|}{ Extrato solubilizado $\left(\mathrm{mg} / \mathrm{L}^{-1}\right)$} & \multirow{3}{*}{$\begin{array}{l}\text { Limite máximo do } \\
\text { extrato }\left(\mathrm{mg} / \mathrm{L}^{-1}\right)\end{array}$} \\
\hline & AM1 & AM2 & AM3 & AM4 & \\
\hline $\mathrm{pH}$ & 9,92 & 8,31 & 9,25 & 10,33 & \\
\hline Alumínio & $<0,01$ & $<0,01$ & 0,07 & 0,310 & 0,2 \\
\hline Arsênio & $<0,001$ & $<0,001$ & $<0,001$ & $<0,001$ & 0,01 \\
\hline Bário & 0,060 & $<0,01$ & $<0,01$ & $<0,01$ & 0,7 \\
\hline Cádmio & 0,103 & 0,112 & 0,051 & 0,080 & 0,005 \\
\hline Chumbo & 0,121 & 0,139 & 0,090 & 0,080 & 0,01 \\
\hline Cobre & $<0,005$ & $<0,005$ & $<0,005$ & $<0,005$ & 2,0 \\
\hline Cromo & 0,116 & 0,086 & 0,198 & 0,260 & 0,05 \\
\hline Ferro & 0,123 & 0,112 & 0,053 & 0,104 & 0,3 \\
\hline Manganês & 0,001 & 0,062 & 0,060 & 0,02 & 0,1 \\
\hline Mercúrio & $<0,001$ & $<0,001$ & $<0,001$ & $<0,001$ & 0,001 \\
\hline Prata & $<0,01$ & $<0,01$ & $<0,01$ & $<0,01$ & 0,05 \\
\hline Selênio & $<0,01$ & $<0,01$ & $<0,01$ & $<0,01$ & 0,01 \\
\hline Sódio & 43,57 & 36,48 & 22,41 & 22,29 & 200,0 \\
\hline Zinco & 0,163 & 0,123 & ND & ND* & 5,0 \\
\hline Nitrato & 4,66 & 2,54 & 3,17 & 7,53 & 10,0 \\
\hline Fenóis totais & 0,001 & $<0,001$ & $<0,001$ & $<0,001$ & 0,01 \\
\hline Sulfato & 198,46 & 328,84 & 285,54 & 292,01 & 250,0 \\
\hline Cloreto & 56,6 & 20,0 & 53,0 & 39,5 & 250,0 \\
\hline Fluoreto & 0,7 & 0,96 & 0,84 & 0,99 & 1,5 \\
\hline Cianeto & $<0,001$ & $<0,001$ & $<0,001$ & $<0,001$ & 0,07 \\
\hline
\end{tabular}

ND: Não detectado na amostra.

locais onde são depositados, aumentando o risco de contaminação de mananciais e contaminando o solo.

As concentrações de sulfato ficaram acima do limite máximo em três das quatro amostras de extrato solubilizado. Apenas na AM1, a concentração de sulfato se mostrou dentro do limite estabelecido pela NBR 10004, embora sua concentração de 198,46 mg/.L-1 tenha se aproximado do limite máximo. Asakura et al. (2010) verificaram que em RCC mistos no Japão é alta a concentração de sulfato (1.100 mg/.. $\left.\mathrm{L}^{-1}\right)$ e atribuem este valor à presença de gesso no RCC.

Segundo Ramos (2007), no material pertencente ao grupo solo e areia é comum a presença de partículas de gesso, difíceis de serem identificadas e retiradas manualmente. Para fabricação do gesso é utilizado como matéria-prima um mineral denomin do gipsita, composto basicamente de sulfato de cálcio hidratado $\left(\mathrm{CaSO}_{4} \cdot 2 \mathrm{H}_{2} \mathrm{O}\right)$. Portanto, a alta concentração de sulfato indica a presença de gesso nos RCC Classe A de Fortaleza. Este dado pode estar confirmado, haja vista ter sido encontrado gesso na composição dos RCC de Fortaleza. Além disso, Oliveira et al. (2011) também constataram a presença de gesso nos RCC desta cidade. Segundo Carneiro.; Brum; Cassa, isso pode provocar fenômenos expansivos em materiais confeccionados com cimento, diminuindo a resistência do concreto e argamassa, entre outros materiais que utilizem RCC como agregado, e o sulfato associado ao cálcio presente no gesso pode causar a dureza permanente da água.

De acordo com a NBR 10004, valores acima do limite máximo permitido para os parâmetros descritos na Tabela 3 classificam o resíduo como não inerte. Nos RCC de Fortaleza, cinco parâmetros apresentaram concentrações acima do limite.

Com base nos resultados acima descritos, verifica-se que, de acordo com a classificação da NBR 10004, os RCC Classe A de Fortaleza devem ser classificados como Classe II-A, ou seja, não perigosos e não inertes. Este resultado contrasta com o usualmente utilizado, pois os resíduos de construção civil geralmente são classificados como Classe II-B (não perigosos e inertes).

Entretanto, Silva e Arnosti Jr. (2007) relataram que os RCC reciclados de Piracicaba apresentaram também concentrações de chumbo, cromo, alumínio e sulfato superiores à permitida, sendo igualmente classificados como Classe II-A. Ramos (2007) é outro autor que classificou os RCC de Vitória como Classe II-A, visto que em suas análises foram verificadas concentrações de alumínio, nitrato e sulfato acima do limite máximo permitido.

Oliveira (2002) registrou que os resíduos de concretos, quando submetidos ao ataque de chuva ácida, liberam compostos formados por sulfato, cádmio, manganês, ferro e alumínio, entre outros, que 
contribuem para a alteração das condições das águas naturais, devendo estes serem classificados como não inertes.

Os resultados obtidos nos ensaios de solubilização, em que alguns parâmetros de metais pesados, como cádmio, chumbo e cromo, e o composto sulfato extrapolam os limites máximos permitidos, inferem sob a possibilidade de contaminação do solo e das águas superficiais e subterrâneas, comprovando a necessidade de ensaios sistemáticos e frequentes dos RCC reciclados, de modo a garantir o uso seguro em relação ao potencial risco ao meio ambiente.

\section{Conclusão}

Os resultados da composição gravimétrica mostraram que os RCC de Fortaleza são compostos, em média, por 24,60\% de areia e solo, 22,00\% de argamassa, 15,60\% de concreto, 14,30\% de cerâmica vermelha, 10,40\% de tijolo branco, 6,30\% de cerâmica de revestimento, 5,00\% de gesso, 1,40\% de outros (plástico, papelão, madeira, vidro e ferro), 0,02\% de espuma, couro e tecido e 0,20\% de embalagens de tinta, solvente e amianto. Desta forma, obtém-se que 93,40\% dos RCC de Fortaleza são classificados como resíduos Classe A; 6,40\% como Classe B; 0,020\% Classe C; e 0,20\% Classe D, conforme classificação da Resolução CONAMA nº 307 (BRASIL, 2002).

As análises do extrato lixiviado apresentaram que nenhum parâmetro ultrapassou os limites máximos permitidos pela NBR 10004 (ABNT, 2004a). Entretanto, isso não ocorreu para o extrato solubilizado, que apresentou parâmetros como alumínio, cádmio, chumbo, cromo e sulfato acima do indicado pela NBR 10004 (ABNT, 2004a). Portanto, de acordo com os resultados obtidos nas análises químicas de toxicidade e solubilidade, os RCC Classe A de Fortaleza não são tóxicos e não são inertes, ou seja, devem ser classificados como Classe II-A - não perigosos e não inertes, de acordo com a NBR 10004 (ABNT, 2004a).

\section{Referências}

ABNT. NBR 10.004: (2004a). Resíduos sólidos - Classificação. Rio de Janeiro: ABNT, $71 \mathrm{p}$

ABNT. NBR 10.005: (2004b). Procedimento para a obtenção de extrato lixiviado de resíduos. Rio de Janeiro: ABNT, $16 \mathrm{p}$.

ABNT. NBR 10.006: (2004c) Procedimento para a obtenção de extrato solubilizado de resíduos sólidos. Rio de Janeiro: ABNT, 3 p.

ABNT. NBR 10.007: (2004d) Amostragem de resíduos sólidos. Rio de Janeiro: ABNT, $21 \mathrm{p}$

ANGULO, S.C. (2005). Caracterização de agregados de resíduos de construção e demolição reciclados e a influência de suas características no comportamento mecânico dos concretos. 2005. 149 p. Tese (Doutorado em Engenharia Civil) - Escola Politécnica, Universidade de São Paulo, São Paulo.

APHA. (2005). Standard methods for the examination of water \& wastewater. $21^{\text {st }}$ ed. Washington: Centennial Edition, 1368 p.

ASAKURA, H.; WATANABE, Y.; ONO, Y.; YAMADA, M.; INOUE, Y.; ALFARO, A.M. (2010). Characteristics of fine processed construction and demolition waste in Japan and method to obtain fines having low gypsum component and wood contents. Waste Management \& Research, v. 28, n. 7, p. 634-646.

ASSUNÇÃO, L.T.; CARVALHO, G.F.; BARATA, M.S. (2007). Avaliação das propriedades das argamassas de revestimento produzidas com resíduos da construção e de demolição como agregado. Exacta, v. 5, n. 2, p. 223-230.

BRASIL. CONSELHO NACIONAL DO MEIO AMBIENTE (CONAMA). Resolução $n^{\circ}$ 307, de 5 de julho de 2002. (2002). Estabelece diretrizes, critérios e procedimentos para a gestão dos resíduos da construção civil. Brasília: Diário Oficial da União.
CABRAL, A.E.B. (2007). Modelagem de propriedades mecânicas e de durabilidade de concretos produzidos com agregados reciclados, considerando-se a variabilidade da composição do RCD. 2007. $254 \mathrm{p}$ Tese (Doutorado em Ciências da Engenharia Ambiental) - Escola de Engenharia de São Carlos, Universidade de São Paulo, São Carlos.

CARNEIRO, A.P.; BRUM, I.A.S.; CASSA, J.C.S. (org.). (2001). Reciclagem de entulho para a produção de materiais de construção: projeto entulho bom. Salvador: EDUFBA - Caixa Econômica Federal, 312 p.

CORNELLI, R.; SCHNEIDER, V.E.; HILLIG, E.; POLETTO, M. (2006). Caracterização de resíduos de construção e demolição (RCD) em dois municípios da serra Gaúcha. In: Congresso de Iniciação Científica em Engenharia Tecnológica, XXI Anais... ljuí: UNIJUÍ, CD-ROM.

EGUCHI,K;TERANISHI,K.;NAKAGOME,A;KISHIMOTO,H.;SHINOZAKI, K.;NARIKAWA,M.Application of recycled coarse aggregate by mixture to concrete construction. Construction and Building Materials, v.21, n.7, p.1542-1551, july 2007

HALMEMAN, M.C.R.; SOUZA, P.C; CASARIN, A.N. (2009). Caracterização dos resíduos de construção e demolição na unidade de recebimento de resíduos sólidos no município de Campo Mourão - PR. Revista Tecnológica, Edição especial ENTECA 2009, p. 203-209.

LIMA, J.H.C. (2008). Utilização de resíduos de construção e demolição para pavimentos urbanos da região metropolitana de Fortaleza. 2008. 185 p. Dissertação (Mestrado em Engenharia de Transportes) - Programa de Mestrado em Engenharia de Transportes, Universidade Federal do Ceará, Fortaleza.

LOVATO, P.S. (2007). Verificação dos parâmetros de controle de agregados reciclados de resíduos de construção e demolição para utilização em concreto. 2007. 180 p. Dissertação (Mestrado em Engenharia Civil) - Programa de Pós-Graduação em Engenharia Civil, Universidade Federal do Rio Grande do Sul, Porto Alegre. 
MAYORGA, R.D.; LIMA, P.V.P.S.; RIOS, A.K.B. CABRAL, A.E.B. (2009). Os resíduos da construção civil e suas implicações socioambientais e econômicas na cidade de Fortaleza - CE. In: Sober - Congresso Sociedade Brasileira de Economia, Administração e Sociologia Rural, 47 Anais... Porto Alegre: SOBER.

NOVAES, M.V. \& MOURÃO, C.A.M.A. (2008). Manual de gestão ambiental de resíduos sólidos da construção civil. Fortaleza: COOPERCON.

OLIVEIRA, E.G. \& MENDES, O. (2008). Gerenciamento de resíduos da construção civil e demolição: estudo de caso da Resolução 307 do CONAMA. Disponível em: <http://www.pucgoias.edu.br/ucg/prope/ cpgss/ArquivosUpload/36/file/Continua/GERENCIAMENTO\%20DE\%20 RES\%C3\%8DDUOS\%20DA\%20CONSTRU\%C3\%87\%C3\%830\%20 CIVIL\%20E\%20DEMOLI\%C3\%87\%C3\%830\%20-\%20ESTUDO\%20 DE\%20CASO\%20DA\%20RESOL_.pdf>. Acesso em: set. 2010

OLIVEIRA,J.C.;REZENDE,L.R.;GUIMARÃES,R.C.;CAMAPUM,J.C.;SILVA,A. L.A.Evaluation of a flexible pavement executed with recycled aggregates of construction and demolition waste in the municipal district of Goiânia-Goiás. In: 2005 INTERNATIONAL SYMPOSIUM ON PAVEMENT RECYCLING, 2005,São Paulo, Anais eletrônicos do 2005 INTERNATIONAL SYMPOSIUM ON PAVEMENT RECYCLING. [CD ROM]. São Paulo, 2005. n.p.

OLIVEIRA, M.E.D.; SALES, R.J.M.; OLIVEIRA, L.A.S.; CABRAL, A.E.B. (2011) Diagnóstico da geração e da composição dos RCD de Fortaleza/ CE. Revista Engenharia Sanitária Ambiental, v. 16, n. 13, p. 219-224.

OLIVEIRA, M.J.E. (2002). Materiais descartados pelas obras de construção civil: estudo dos resíduos de concreto para reciclagem. 2002. 191 p. Tese (Doutorado em Engenharia Civil) - Instituto de Geociências e Ciências Exatas, Universidade Estadual Paulista, São Carlos.
RAMOS, B.F. (2007). Indicadores de qualidade dos resíduos da construção civil do município de Vitória-ES. 2007. 161 p. Dissertação (Mestrado em Engenharia Ambiental) - Centro Tecnológico, Universidade Federal do Espírito Santo, Vitória.

SANTOS, E.C.G. (2007). Aplicação de resíduos de construção e demolição reciclados (RCD-R) em estruturas de solo reforçado. 2007. 168 p. Dissertação (Mestrado em Geotecnia) - Escola de Engenharia de São Carlos, Universidade de São Paulo, São Carlos.

SCHAEFER, C.O.; ROCHA, J.C.; CHERIAF, M. (2007) Estudo do comportamento de lixiviação de argamassas produzidas com agregados reciclados. Exacta, v. 5, n. 2, p. 243-252.

SILVA, R. \& ARNOSTI JR., S. Caracterização do resíduo de construção e demolição (RCD) reciclado. Holos Environment, v. 5, n. 2, 2007, p. $137-151$

TOGERÖ, A. (2004). Leaching of hazardous substances from concrete constituents and painted wood panels. 2004. 133 p. Tese (Doutorado em Tecnologia de Construção) - Department of Building Technology, Chalmers University of Technology, Göteborg, Suécia.

ULSEN, C.; KAHN, H.; ANGULO, S.C.; JOHN, V.M. (2010) Composição química de agregados mistos de resíduos de construção e demolição do Estado de São Paulo. Revista Escola de Minas, v. 63, n. 2., p. 339-346.

VAZQUEZ, E. (2001). Aplicación de nuevos materiales reciclados en la construcción civil. In: Seminário de Desenvolvimento Sustentável e a Reciclagem na Construção Civil, 4 Anais... São Paulo: IBRACON. 